CAnstitute $\begin{gathered}\text { CARADDE: Jurnal Pengabdian Kepada Masyarakat } \\ \text { https://journal.ilininstitute.com/index.php/caradde } \\ \text { Volume 2 I Nomor 1 I Agustus |2019 } \\ \text { e-ISSN: 2621-7910 dan p-ISSN: 2621-7961 }\end{gathered}$
DOI: https://doi.org/10.31960/caradde.v2i1.244

\title{
Penerapan Self Monitoring Program Tingkat Aktifitas Fisik Usia Lanjut di Posyandu Anyelir Bekasi
}

\author{
Budi Sarasati $^{1}$, Iin Widyasatuti ${ }^{2}$, Rafi Saridayani ${ }^{3}$, Veny Kurniasari ${ }^{4}$, Sofyan Farid Maarif ${ }^{5}$
}

\begin{tabular}{ll}
\hline Keywords: & Abstrak. Tujuan Pengabdian Masyarakat ini adalah untuk \\
pengkajian kebutuhan; & menerapkan alat monitoring aktifitas fisik untuk para \\
self-efficacy; & lanjut usia yang tinggal di wilayah Puskesmas Aren Jaya \\
dukungan social; & Kecamatan Bekasi Timur kota Bekasi. Praktek monitoring \\
tingkat aktifitas fisik; & aktifitas lansia menggunakan buku saku berjudul "FIT- \\
program self-monitoring. & Pro", yang didalamnya terdapat PACE ( Patient-Centered \\
& Assessment and Counceling for Exercises ), yang \\
Corespondensi Author & dimodifikasi sesuai dengan aktifitas fisik usia lanjut di \\
Bidang ilmu; Psikologi & Indonesia. Alat ini untuk mengukur tingkat aktifitas fisik, \\
Universitas Bhayangkara Jakarta & dukungan sosial dan self-efficacy responden. Partisipan \\
Raya & adalah masyakat kelompok umur usia lanjut yang ada di \\
Jl. Raya Perjuangan, Margamulya, & daerah tersebut di atas, berjumlah 35 orang. Pelaksanaan \\
Bekasi Barat & penerapan Self Monitoring Program melibatkan provider \\
Email: & kesehatan di wilayah kerja Puskesmas Aren Jaya \\
budi.sarasatiubj@,dsn.ubharajaya.ac.id & Kecamatan Bekasi Timur Kota Bekasi. Hasil pelaksanaan \\
History Artikel & menunjukkan bahwa kelompok usia lanjut di wilayah Aren \\
Received: Juni-2019; & Jaya belum melaksanakan self monitoring aktifitas \\
Reviewed: Juni -2019 & kesehatan fisiknya secara teratur. Kesimpulan nya adalah \\
Accepted: Juli-2019 & Self Monitoring Program dapat diterapkan untuk lanjut \\
Published: Agustus-2019 & usia dalam mempertahan aktifitas fisik sehari-hari, agar \\
& tercapai kesehatan yang optimal. Selama pelaksanaan Self \\
& Monitoring Program para lansia dan keluarga mencatat \\
& hambatan yang dirasakan, agar pedoman dapat direvisi
\end{tabular}

(1) This work is licensed under a Creative Commons Attribution

4.0 International License

\section{PENDAHULUAN}

Pengabdian Masyarakat ini di latar belakangi dari Needs Assessment aktifitas fisik kelompok usia lanjut di lingkungan masyarakat Aren Jaya Bekasi. Pola aktifitas fisik para lanjut usia menunjukkan tingkatan yang berbeda. Walaupun tersedia sarana dan prasarana, atau perlakuan yang sama dari petugas/care giver, tetapi faktor individu dan dukungan keluarga mempengaruhi perilaku aktifitas fisik mereka.

Ballesteros, et.al., (2002) membahas Self-efficacy kolektif akan terbentuk setelah lanjut usia tersebut tinggal di daerah yang sama, selalu melakukan kegiatan bersamasama, melakukan hobi bersama, dan dalam suatu komunitas yang sama. Kenyataanya para lanjut usia yang tinggal di wilayah Aren Jaya belum menunjukkan tingkat aktifitas fisik yang baik. 
Aktifitas fisik adalah kegiatan tubuh termasuk setiap perpindahan massa tubuh yang dihasilkan oleh kontraksi dari otot dan tulang dan yang sangat substansial meningkatkan pengeluaran energi ( Pajares \& Urdan, 2006: 162 ). Kegiatan yang termasuk aktifitas fisik ini antara lain olah raga (exercise ), menari (dance) dan aktifitas fisik di waktu luang $(\mathrm{PLTA}=$ Physical Leisure Time Activities). Aktifitas fisik dipengaruhi oleh beberapa faktor, antara lain : umur, keadaan status kesehatan individu seperti adanya penyakit kronis, keadaan psikososial, serta faktor mekanik seperti kekuatan tubuh, keadaan obesitas dan Body Mass Index (BMI). Banyak penelitian yang membuktikan bahwa aktifitas fisik yang rutin dilakukan berdampak pda kesehatan psikologis dan fisik yang paripurna, serta mencegah penyakit-penyakit kronik dan kematian dini. Aktifitas fisik yang dilakukan secara teratur juga dapat menurunkan resiko individu terkena penyakit kronik, termasuk obesitas, beberapa jenis kanker tertentu, diabetes, serta masalah kesehatan lain seperti serangan jantung dan hipertensi ( Gorin \& Arnold, 2006 ).

Studi dari King ( 2001 ) menyatakan bahwa pendekatan personal dan interpersonal untuk aktifitas fisik lebih tepat menggunakan langkah-langkah seperti penentuan tujuan bersama, self-monitoring, feedback, support, stimulus control, dan relapse-prevention training, dari pada hanya pendidikan kesehatan, anjuran latihan dan sekedar instruksi saja.

Penelitian beberapa ahli tentang selfmonitoring ini, membuat mereka membagi dua prototipe individu menjadi : 1). Individu high in self-monitoring. Ciri-ciri dari individu jenis ini adalah mereka menunjukkan respon yang baik pada kejadian di masyarakat dalam situasi sosial tertentu. Selain itu individu jenis ini juga berusaha untuk menyesuaikan perasaan dan perilaku mereka pada situasi tertentu yang tidak diharapkan. Ciri lain adalah individu mempunyai ketrampilan mengkomunikasikan perasaannya dengan tepat melalui bahasa verbal dan nonverbal. 2). Individu low in self-monitoring. Kebalikan dari individu dengan high self-monitoring, individu tipe low mempunyai ciri-ciri memperlihatkan perhatian yang rendah terhadap situasi sosial, dan lebih perhatian terhadap diri sendiri. Mereka mengekspresikan perilaku sesuai dengan tingkat afeksi diri dan sikap pribadi atau pada apa yang dirasakannya.

Berdasarkan observasi peserta posyandu dan wawancara kepada provider ( petugas Puskesmas ), yang dilakukan oleh penulis dan tim pengabdian masyarakat Fakultas Psikologi, maka terdapat beberapa masalah di Posyandu Anyelir, Kecamatan Aren Jaya Bekasi Timur, antara lain : a) Belum ada program khusus yang dapat memantau secara mandiri aktifitas fisik untuk usia lanjut, b) Belum ada panduan bagaimana menangani kelompok usia lanjut yang tidak mau beraktifitas secara rutin.

Dari kedua masalah tersebut di atas, diharapakan dengan adanya alat ukur tingkat aktifitas fisik, maka anggota keluarga yang mempunyai lanjut usia dapat ikut memantau tingkat kesehatan fisik mereka, dan para usia lanjut dapat melakukan sendiri pengukuran level aktifitas fisik mereka.

\section{METODE}

Pengabdian masyarakat ini diselenggarakan pada bulan Juni 2016 sampai dengan Agustus 2016, bertempat di Posyandu Anyelir, wilayah kerja Puskesmas Aren Jaya Kecamatan Bekasi Timur kota Bekasi. Tempat ini dipilih dengan beberapa alasan, yaitu : tempat strategis, Posyandu Anyelir mempunyai program pembinaan warga usia lanjut, Posyandu Anyelir juga dikelola secara baik oleh kader, sehingga secara administratif pencatatan data pengunjung dan klien juga baik. mudah menghimpun para usia lanjut bila diperlukan, karakteristik lanjut usia cenderung homogen, terdapat care giver dari latar belakang kesehatan ( dokter dan perawat ) dari Posyandu terdekat dan Pekerja Sosial.

Partisipan adalah seluruh Lanjut Usia yang berada di wilayah kerja Puskesmas Aren Jaya, berjumlah 35 orang, dengan memakai proses seleksi bersyarat yaitu : Lanjut Usia yang tinggal di wilayah binaan Posyandu Anyelir dan wilayah kerja Puskesmas Aren Jaya, tidak mengalami gangguan pendengaran, dapat berkomunikasi ( menggunakan bahasa Indonesia ), jenis kelamin laki-laki maupun perempuan, tidak sedang menderita sakit yang parah sehingga tidak dapat melakukan aktifitas sehari-hari (seperti sedang dirawat atau bed rest total). 
Kegiatan Self Monitoring Program menggunakan panduan sebuah buku kecil atau buku saku yang berisi langkah-langkah pengkajian aktifitas fisik, yang disebut sebagai PACE ( Patient-Centered Assessment and Counceling for Exercises ) yang dimodifikasi sesuai dengan aktifitas fisik yang biasa dilakukan oleh para Lanjut Usia di Indonesia secara umum. Format PACE ini terdiri dari dua buah yaitu : Format Status Aktifitas Fisik Klien Saat Ini, terdiri dari 8 item. Item pertama adalah tingkat pre-contemplation, item 2 adalah tingkat contemplation, item 3 dan 4 adalah tingkat aktifitas preparation, item 5,6 dan 7 adalah tingkat active, dan item 8 adalah maintenance.

\section{HASIL DAN PEMBAHASAN}

Tahap Persiapan

Pada tahap ini tim Pengabdian Masyarakat fakultas Psikologi ( selanjutnya disebut Pengmas ) melaksanakan advocacy berupa surat menyurat ke Dinas Kesehatan Kota Bekasi untuk meminta persetujuan melaksanakan Pengmas di Puskesmas Aren Jaya. Setelah mendapatkan balasan surat dari Dinas Kesehatan, selanjutnya tim mengantarkan surat tersebut ke Kepala Puskesmas. Kepala Puskesmas menunjuk Bidan pembina Puskesmas. Terpilih Posyandu Anyelir yang terletak di RW 20 Kelurahan Aren Jaya, dengan pertimbangan Posyandu tersebut terletak di pinggir jalan dan mudah dijangkau angkutan umum maupun dengan mobil pribadi. Selain itu Posyandu Anyelir mempunyai gedung yang cukup representatif untuk dilaksanakan Pengmas, kemudian kader Posyandu tersebut juga aktif dalam melaksanakan program Puskesmas.

Kegiatan selanjutnya adalah mendata dan mengelompokkan peserta Posyandu usia lanjut yang masuk kategori High in Self Monitoring berjumlah 20 orang ( $57,1 \%$ ) dari 35 orang usila. Sisanya sejumlah 15 ( 42,9\%) orang termasuk kategori Low in Self Monitoring. Pengukuran menggunakan PACE.

\section{1) Tahap Pelaksanaan}

Adapun rangkaian kegiatan dalam rangka sosialisasi SMP ini meliputi beberapa tahap, yaitu : a) Tahap I : Workshop mini ( bulan Juni )

Tujuan dari kegiatan ini adalah penyamaan persepsi tentang penggunaan buku Manual Aktifitas Fisik. Kegiatan ini di hadiri oleh provider, meliputi dokter Puskesmas wilayah Aren Jaya, Petugas Lapangan, dan Kader Kesehatan. Penyamaan persepsi meliputi hal-haltentang aktifitas fisik (pengertian, tujuan dan manfaat, faktor-faktor yang mempengaruhi aktifitas fisik, jenis-jenis aktifitas fisik untuk lanjut usia, aktifitas fisik untuk lanjut usia yang sakit, mencapai aktifitas fisik yang optimal) Kegiatan ini berlangsung tanggal 12 Agustus 2016, bertempat di Posyandu Anyelir dan dihadiri sekitar 15 orang.

\section{b) Tahap II :Sosialisasi (bulan Juli)}

Sosialisasi buku Manual Self Monitoring Programme untuk para Lanjut Usia yang tinggal di wilayah Aren Jaya, meliputi : pengertian, tujuan dan manfaat, kendalakendala untuk beraktifitas fisik, sekaligus pemeriksaan kesehatan oleh kader kesehatan Posyandu pada sekitar 35 orang kelompok usia lanjut.

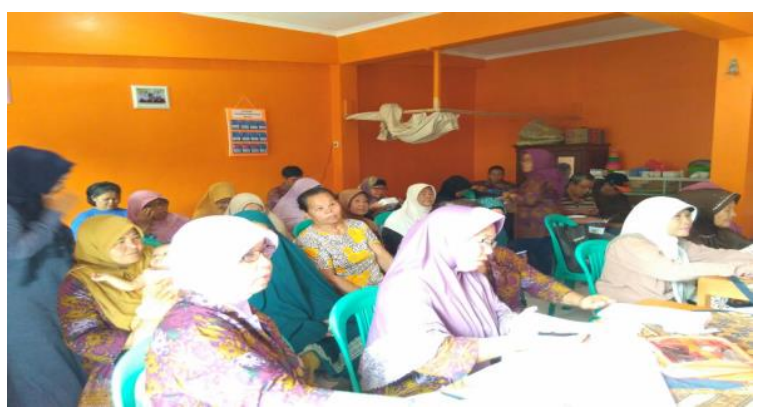

Gambar 1 : Sosialisasi Buku Manual Self Monitoring Programe

c) Tahap III : Pemeriksaan kesehatan secara umum ( bulan Juli 2016 )

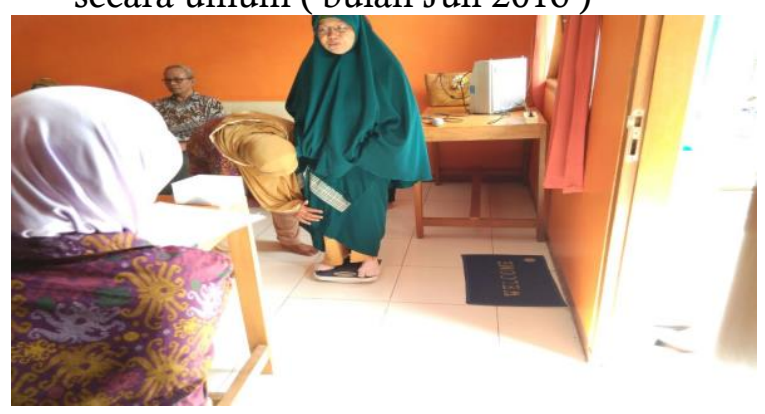

Gambar 2 : Pemeriksaan kesehatan umum Kelompok Usia Lanjut 
Caradde: Jurnal Pengabdian Kepada Masyarakat Vol 2 No 1, Agustus 2019

Hasil dari pemeriksaan kesehatan secara umum adalah sebagai berikut : Kelompok umur paling dominan adalah kelompok umur 61-67 tahun sebesar 41,79\%, kemudian kelompok umur 68-74 tahun sejumlah $34,33 \%$ dan yang paling sedikit adalah kelompok umur 54-60 tahun serta 8288 tahun.

Adapun data demografik mereka adalah sebagai berikut : agama yang dianut oleh usia lanjut ada dua agama, yaitu Islam sebanyak $86,57 \%$ dan Kristen sebanyak $13,43 \%$. Tingkat pendidikan para usial lanjut didominasi oleh lulusan SD ( $31,34 \%$ ), SMP sebesar $17,91 \%$, SMA $50,1 \%$, dan sisanya tidak sekolah $0,68 \%$.. Etnis yang paling banyak adalah Jawa sebesar $26,87 \%$ dan disusul kemudian Sunda 14,93\%, sedangkan etnis lainnya berasal dari Sumatra dan Kalimantan. Latar belakang pekerjaan mereka paling banyak adalah dari umum/swasta (seperti pedagang, buruh pabrik, pegawai kantor swasta, dan lain-lain) sebesar 73,13\%, dan veteran sejumlah 8,96 $\%$.

d) Tahap IV : Klasifikasi tingkat aktifitas fisik.

Langkah selanjutnya memilah responden menjadi beberapa kelompok berdasarkan tingkat aktifitas fisik yang sudah terkaji. Terdapat 16 orang tingkat precontemplation, satu orang tingkat preparation, 16 orang tingkat active, dan dua orang tingkat maintenance. Kemudian menentukan tujuan berkala bersama-sama klien, care giver dan keluarga yang ikut hadir saat itu. Selanjutnya menentukan beberapa alternatif aktifitas fisik yang dapat dilakukan oleh klien dan feed back. Penelitian menunjukkan bahwa dukungan sosial lebih berpengaruh terhadap aktifitas fisik, dibandingkan dengan self-efficacy. Hal ini dapat dijadikan sebagai pedoman dalam menentukan support group mereka. Langkah selanjutnya adalah melibatkan peran dokter secara aktif. Tim pengmas bersama para usia lanjut membentuk latihan yang baik meliputi aspek : frekuensi, waktu, intensitas dan kemajuan latihan.

e) Tahap V : Kegiatan Penyuluhan dan Pendidikan Kesehatan.
Kegiatan ini berlangsung pada tanggal 22 Agustus 2016, bertempat di Posyandu Anyelir. Kegiatan ini dihadiri oleh Petugas Lapangan Puskesmas, Seluruh Kader Kesehatan Posyandu, serta tim Pengabdian Masyarakat. Kegiatan ini berjalan lancar dan klien cukup responsif. Terbukti beberapa klien menanyakan tentang aktifitas fisik yang dianjurkan untuk mereka yang mengidap berbagai macam penyakit degeneratif seperti jantung, ginjal dan diabetes mellitus. Di hari tersebut dibagikan sekitar 50 buku Manual SMP untuk klien dan Kader Posyandu.

\section{f) Tahap VI : Penerapan SMP.}

Penerapan SMP ditandai dengan penyerahan 125 buku Manual SMP ke pada pihak Puskesmas, untuk selanjutnya dapat dibagikan ke klien yang berobat ke Puskesmas. 25 buku lagi dibagikan ke Posyandu Anyelir. Diharapkan tiga bulan setelah kegiatan sosialisasi dan penyuluhan tentang aktifitas fisik pada usia lanjut dapat dilakukan evaluasi program, apakah buku Manual SMP ini berdampak positif pada klien usia lanjut dalam mempertahankan tingkat aktifitas fisik mereka secara mandiri.

\section{g) Tahap Evaluasi}

Tahap Evaluasi dilaksanakan bersifat formatif. Setelah dilakukan penyuluhan dan pendidikan tentang kesehatan umumnya dan tingkat aktifitas fisik oleh tim Pengmas fakultas Psikologi, langsung di laksanakan tanya jawab tentang materi penyuluhan. Terdapat enam orang yang aktif bertanya, dan dijawab dengan baik oleh tim pengmas, dan juga dari petugas lapangan Puskesmas. Kegiatan evaluasi ini diakhiri dengan foto bersama dan penyerahan tanda mata kepada petugas Puskesmas, bapak RW dan ketua kader Posyandu Anyelir.

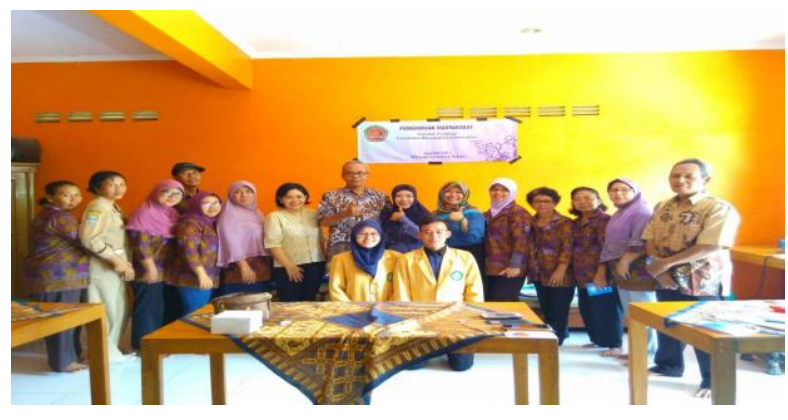

Gambar 3 : Penutupan Kegiatan PKM 


\section{Pembahasan}

Penelitian ataupun studi tentang aktifitas fisik, oleh ahli di luar negeri sudah banyak dilakukan. Mereka menggunakan pendekatan yang berbeda dalam melihat fenomena aktifitas fisik ini, khususnya yang terjadi pada lanjut usia. Studi Van Heuelen, et.al., ( 2006 ), melakukan suatu psychological dan physical activity training pada 118 obyek lanjut usia berusia 65-92 tahun. Mereka menilai bahwa kesuksesan training atau latihan yang mereka selenggarakan dinilai dari prosentasi dan tingkat kehadiran para lanjut usia tersebut. Kemudian ternyata ditemukan bahwa tingkat kehadiran responden dipengaruhi oleh derajat keaktifan dari Activity Daily Living ( ADL ) mereka sehari-hari dimana para responden tersebut tinggal. Para lanjut usia yang mempunyai karakteristik berjalan dengan pelan mempunyai resiko lebih banyak tidak hadir dalam acara training. Selain itu ditemukan mereka yang tinggal bersama pasangan hidup lebih banyak tingkat kehadirannya dibandingkan dengan lanjut usia yang hidup sendiri atau terpisah dari keluarganya.

Penelitian oleh McAuley, et.al., ( 2005 ), melihat hubungan antara aktifitas fisik dan self-efficacy yang mempengaruhi tingkat selfesteem lanjut usia. Sampel yang dipakai sebanyak 174 lanjut usia berusia antara 60-75 tahun, yang aktif mengikuti latihan selama enam bulan, tinggal menetap ( tidak berpindah-pindah ), termasuk lanjut usia yang ditemui pada satu dan lima tahun setelah mengikuti program latihan. Hasil penelitian menunjukkan bahwa aktifitas fisik yang reguler dilaksanakan akan membuat tubuh menjadi lebih menarik, kuat dan tidak mudah jatuh sakit. Hal ini menyebabkan meningkatnya physical self-esteem, yang pada akhirnya akan mempengaruhi global self-esteem para lanjut usia dalam kehidupan mereka sehari-hari.

Richeson, Croteau, Jones \& Farmer, ( 2006 ), melakukan eksperimen pada lanjut usia, menggunakan sebuah alat berupa Yamax Digi-Walker Sw-200, yaitu pedometer elektronik yang dipasang pada responden lanjut usia. Alat ini untuk mengukur penampilan fisik (terdiri dari keseimbangan, gaya berjalan, dan kekuatan anggota gerak bagian bawah). Alat tersebut dipasang di tubuh responden sepanjang hari selama tujuh hari. Setelah itu responden segera mengikuti program intervensi social cognitive theory, terdiri dari konseling, pedometer dan selfmonitoring. Penelitian eksperimen ini menggunakan grup kontrol dan metode pretest-posttest terhadap 147 partisipan berumur 55-94 tahun dan masa intervensi selama 12 minggu. Hasil eksperimen menunjukkan grup intervensi lebih meningkat kecepatan alat pedometernya. Itu berarti mobilitas fisik responden yang mendapatkan intervensi lebih baik dibandingkan dengan grup kontrol yang tidak mendapatkan intervensi terlebih dulu ( hanya dipasang alat pedometer saja ). Mobilitas fisik yang baik menyebabkan selfefficacy para lanjut usia menjadi lebih meningkat. Berdasarkan pengukuran self efficacy para usia lanjut menunjukkan dari 35 orang responden, terdapat satu orang $(2,9 \%)$ yang memiliki self efficacy rendah, 18 orang $(51,4 \%)$ memiliki self efficacy sedang, dan 16 orang $(45,7 \%)$ memiliki self efficacy tinggi.

Singh, ( 2002 ), meneliti tentang keharusan latihan untuk lanjut usia, agar dapat meminimalkan perubahan fisiologis. Perubahan fisiologis yang terjadi, diharapkan tidak mempengaruhi kesehatan mental dan kesejahteraan para lanjut usia. Hasil penelitian Singh ini berguna untuk memilih aktifitas fisik yang tepat bagi lanjut usia dengan berbagai kondisi fisik akibat menderita penyakit kronik. Latihan yang tepat dapat meningkatkan massa otot dan pergerakan tubuh, fungsi jantung, paru-paru, kerja hormon-hormon tubuh ( metabolic miscellaneous ) dan status gizi lanjut usia.

King, ( 2001 ), memberikan pandangan tentang pendekatan personal dan interpersonal guna melakukan intevensi aktifitas fisik adalah menggunakan strategi cognitive-behavioral. Cara ini lebih efektif dibandingkan dengan pendidikan kesehatan, latihan terstruktur atau perintah saja. Strategi tersebut meliputi : menentukan tujuan, selfmonitoring, feedback, support, stimulus control dan relapse-prevention training.

Penerapan Self Monitoring Program ini adalah kegiatan yang penting untuk meningkatkan kualitas hidup para usia lanjut. Dengan menggunakan panduan Self Monitoring Program ini diharapkan para usia lanjut dapat memantau tingkat aktifitas fisiknya sehari-hari dan memelihara 
Caradde: Jurnal Pengabdian Kepada Masyarakat

Vol 2 No 1, Agustus 2019

kesehatan secara optimal. Bagi anggota keluarga, diharapkan buku panduan SMP dapat mendeteksi dini dan mencegah bila ada gagguan kesehatan pada anggota keluarganya yang usia lanjut. Sedangkan bagi provider kesehatan, buku panduan SMP diharapkan bisa meningkatkan upaya promotif dan preventif pada usia lanjut di daerah binaan.

\section{SIMPULAN DAN SARAN}

Kesimpulan dari kegiatan pengabdian masyarakat ini adalah: (1) Diperlukan pemantauan yang kontinyu tentang derajat kesehatan usia lanjut di masyarakat, khususnya tingkat aktifitas fisik mereka; (2) Diperlukan kerjasama yang baik antara Puskesmas, Kader Posyandu dan tim Pengabdian Masyarakat dari Institusi Pendidikan; (3) Diperlukan Evaluai Program setiap tiga bulan tentang manfaat dari buku Manual tingkat aktifitas fisik usia lanjut.

Dengan demikian, agar kegiatan lanjutan lebih baik lagi maka, tim pengabdian masyarakat menyarankan: (1) Terdapat buku Evaluasi program triwulanan; (2) Diskusi rutin antara tim Pengabdian Masyarakat Institusi Pendidikan dengan Puskesmas dan Kader Posyandu untuk membuat perbaikan buku Manual

\section{DAFTAR RUJUKAN}

Ballesteros, R.F., Nicolas, J.D., Caprara, G.V. and Barbaranelli, C., Bandura, A., ( 2002 ), Determinants and Structural Relation of Personal Efficacy to Collective Efficacy, ( 1 ), pg. 107125, International Association for Applied Psychology, Blackwell Publishers.

Gorin, S. S., \& Arnold, J., ( 2006 ), Health Promotion in Practice, Jossey-Bass; A Wiley Imprint, San Francisco.

King, A. C., ( 2001 ), Interventions to Promote Physical Activity by Older Adults, The Journals of Gerontology; Oct 2001; 56A, Academic Research Library. $\quad$ Pg. 36. (http://www.proquest.com.pqdweb, diakses 24 Maret 2015)

McAuley, et. al., ( 2006 ), Physical Activity and Functional Limitations in Older Women: Influence of Self-Efficacy, The Journals of Gerontology; Sept 2005; 61B, 5; Academic Research Library, pg. 270 , (http://www.proquest.com/pqdweb, diakses 24 Maret 2015)

Pajares, F., dan Urdan, T., ( Eds ), ( 2006 ), Self-efficacy Beliefs of Adolescents, Informational Age Publishing, Greenwich, Connecticut.

Richeson, N.E., Croteau, K.A., Jones, D.B., \& Farmer, B.C., ( 2006 ), Effect of a Pedometer-Based Intervention on the Physical Performance and MobilityRelated Self-Efficacy of CommunityDwelling Older Adults; An Interdisciplinary Prevention, Therapeutic Recreation Journals; First Quarter 2006; 40, 1; ProQuest Psychology Journals pg. 18. (http://www.proquest.com/pqdweb, diakses 24 Maret 2015)

Singh, M. A. F., ( 2002 ), Exercise Comes of Age: Rationale and Recommendations for a Geriatric Exercise Prescription, The Journals of Gerontology; May 2002; 57A, 5; Academic Research Library, pg. M262, (http://www.proquest.com/pqdwb, diakses 24 Maret 2015)

Van Heuvelen, M.J.G., Hochstenbach, Brouwer, deGreef, M.H.G., dan Scherder, E., ( 2006 ), Psychological and Physical Activity Training for Older Persons: Who Does Not Attend?, The Journals of Gerontology; August 2006; 52; Behavioural Science Section, $\quad$ pg. 366-375, (http://www.proquest.com/pqdwb, diakses 21 Maret 2015) 